\title{
H. VAN DER WEE
}

Noordegraafs recente boek 'Hollands Welvaren'? heeft aanleiding gegeven tot een uitvoerige bespreking door Jan de Vries, een bespreking die is uitgelopen op een levendige discussie tussen auteur en recensent.

De discussie situeert zich op een dubbel niveau. De resultaten van het onderzoek worden vergeleken met die van andere onderzoekers en deze vergelijking wordt door de twee discussianten kritisch doorgelicht. Voorts wordt de methodologie, waarop het onderzoek berust, aan een grondige analyse onderworpen: de analyse beperkt zich hier niet tot een kritische evaluatie van de methodologische toepassingen in het boek zelf, maar deint uit tot een bredere gedachtenwisseling over de fundamentele vragen van de historische methodologie, zoals heuristiek, bronnenkritiek, modelmatige versus beschrijvende interpretatie, enz.

De methodologische discussie neemt het leeuwedeel voor zich. Onze aantekening zal dit overwicht weerspiegelen, maar toch zal worden gestreefd om het belang van de behandelde thematiek en dit van de bekomen resultaten eveneens aan bod te laten komen.

De levensstandaard oefende reeds in de late middeleeuwen en in de nieuwe tijd een directe invloed uit op de sociale en economische ontwikkeling: ook de demografische, politieke en religieuze realiteit werd erdoor beroerd. Over de geschiedenis van de levensstandaard in Holland tijdens de betrokken periode was slechts sporadisch onderzoek ondernomen en dan nog wel aan de hand van zeer beperkt bronnenmateriaal. De poging van Noordegraaf om deze lacune te vullen moet dan ook als zeer lofwaardig worden geprezen. Hier werd belangrijk pionierswerk verricht: daar is iedereen het over eens.

Noordegraaf duidt expliciet aan dat zijn studie slechts een eerste poging tot diepgaand onderzoek betreft, en dat qua heuristiek en interpretatie nog dieper kan worden gegraven. De conclusies die worden gepresenteerd, zijn aldus slechts het resultaat van de 'riemen waarmee hij geroeid heeft'. De Vries reageert hiertegen. Wilde Noordegraaf een diepgaand onderzoek ondernemen, dan had hij nog dieper moeten graven dan hij effectief gedaan heeft en dan had hij moeten zorgen dat de riemen waarmee hij roeide van betere kwaliteit waren. Daar Noordegraaf niet zover is gegaan als De Vries noodzakelijk achtte, noemt laatstvernoemde de poging van Noordegraaf tot diepgaand onderzoek een slag in het water. Noordegraaf daarentegen blijft overtuigd dat op het gebied van de historische kennis van de levensstandaard in Holland door zijn onderzoek een reële vooruitgang is geboekt: deze kennis steunt thans op veel steviger feitenmateriaal.

Om de twee standpunten zinvol te kunnen evalueren, is het nuttig de aandacht achtereenvolgens toe te spitsen op de specifiëring van de vraagstelling, op de gevolgde heuristiek, op de gebruikte methodologie, en op de afgeleide interpretatie.

Voor wat de vraagstelling betreft, wordt het concept 'levensstandaard in Holland' in het boek onvoldoende gespecificeerd. De levensstandaard wordt eenvoudig bepaald als de 'materiële positie van de bevolking in het gewest Holland': dit is wel een zeer vage 
omschrijving van een zeer complexe realiteit. De materiële positie van de bevolking van Holland, tijdens de periode 1450-1650, is inderdaad geen homogeen gegeven: grote verschillen deden zich voor tussen stad en platteland, tussen de ene stad en de andere, tussen de ene rurale subregio en de andere, tussen de sociale geledingen van iedere stad of subregio. De onderlinge verschillen in levensstandaard wijzigden zich bovendien doorheen de tijd: in een bepaalde stad kon de onderlinge verhouding tussen de lage, middelhoge en hoge inkomensgroepen zich wijzigen doorheen de tijd in vergelijking tot de andere steden; analoge wijzigingen konden zich voordoen wanneer stad en platteland onderling worden vergeleken. Hierbij aansluitend stelt zich het probleem van het consumptiepatroon: steden en platteland hadden ieder hun eigen consumptiepatroon qua voeding, behuizing, kleding en schoeisel, enz.; iedere sociale geleding zowel in de stad als op het platteland hield er eigen consumptiegewoonten op na, die bovendien tussen 1450 en 1650 veranderden. Tenslotte mag het aspect 'autoconsumptie' niet uit het oog worden verloren. De Hollandse steden waren in de loop van de veertiende en vijftiende eeuw nog kleine centra, waar de meeste inkomensgroepen hun voedingswaren niet uitsluitend langs de markt verwierven, maar ook via eigen produktie of via betalingen in natura voor arbeid in de stad of op het nabije platteland. Voor de rurale inkomensgroepen is het belang van de eigen produktie of van de betalingen in natura nog groter. Bovendien is er het probleem van wijzigingen in deze verhoudingen tussen 1450 en 1650 .

Door de gebrekkige specifiëring van de concepten blijven tijdens het onderzoek enkele essentiële vragen, zoals die betreffende de consumptiegewoonten, de autoconsumptie en de betalingen in natura, zo goed als onaangeroerd. Als gevolg hiervan wordt de kwantitatieve studie betreffende de ontwikkeling van de levensstandaard beperkt tot het vaststellen van de verhoudingen tussen lonen en prijzen in Holland tussen 1450 en 1650, en wordt deze kwantitatieve studie aangevuld met een kwalitatief onderzoek over de invloed van de werkloosheid, de weersomstandigheden, de epidemieën, de fiscaliteit, en de oorlogen.

Deze laatste kwalitatieve aanvulling betekent een aanzienlijke verrijking in de studie van de levensstandaard, en werd door De Vries terecht als belangrijk aangezien. Tegen de kwantitatieve analyse oppert De Vries een reeks methodologische bezwaren, die grotendeels verantwoord zijn indien Noordegraaf de titel van zijn boek wenst te handhaven.

Hiermede zijn we beland in het tweede deel van ons betoog, dat de heuristiek en de bronnenkritiek in de voorliggende discussie tot voorwerp heeft.

Voor wat de inkomensontwikkeling betreft is de geselecteerde steekproef (met name de studie van de lonen van metselaars en opperlieden te Haarlem en Leiden) niet voldoende representatief om er het verloop van de levensstandaard in het hele gewest Holland uit te mogen afleiden. De evolutie op het Hollandse platteland was ongetwijfeld specifiek, niet alleen sowieso, maar ook omdat de landbouweconomie er juist tijdens de betrokken periode belangrijke structuurveranderingen doormaakte. Haarlem en Leiden zijn voor de Hollandse steden al evenmin representatief: beide steden doorliepen een specifieke economische ontwikkelingscyclus die tot een specifiek loonpeil en tot een specifieke looncurve aanleiding gaf. Hetzelfde kan worden gezegd van de andere Hollandse steden. Wie de lonen van de Zuidnederlandse steden tijdens deze periode heeft bestudeerd, weet 
hoezeer uiteenlopend het peil en de ontwikkeling van de lonen kunnen zijn zelfs van steden die nauwelijks $17 \mathrm{~km}$ van elkaar verwijderd liggen.

De representativiteit van daglonen voor het stedelijk inkomen kan eveneens in twijfel worden getrokken. De midden- en topinkomens vormden in de Hollandse steden een niet te verwaarlozen groep, en in deze groep domineerden eerder de kleine ondernemingen en het zelfstandige inkomen. De representativiteit van de bouwsector voor het geheel van de stedelijke loonsontwikkeling is al evenmin gewaarborgd: tijdens perioden van langdurige stedelijke expansie overschatten bouwionen meestal de gemiddelde loonsontwikkeling, tijdens perioden van langdurige contractie of stagnatie lijden ze aan onderschatting. Een bredere invalshoek dan die van de bouwsector, zelfs indien minder continue loonreeksen hierin werden opgenomen, ware bijgevolg wenselijk geweest.

De discussie betreffende het aantal loonreeksen verwijst bovendien naar het probleem van de bronnenkritiek. De kritiek van De Vries op de door Noordegraaf gebruikte bouwlonen valt negatief uit. Aan de voorwaarde van homogeniteit blijkt inderdaad niet altijd te zijn voldaan: de daglonen dekken op het eerste gezicht niet altijd dezelfde aard van werk, dezelfde vergoeding (bijvoorbeeld: daglonen met of zonder maaltijd, met of zonder leerknaap), hetzelfde seizoen. Een jarenlange ervaring in loononderzoek heeft geleerd hoe moeilijk het in de praktijk is om de voorwaarde van homogeniteit te verwezenlijken. Noordegraaf heeft herhaaldelijk beklemtoond dat het Hollandse bronnenmateriaal op dit punt zeer weerbarstig is. Toch een bemerking in dit verband: de toepassing van de prosopografische methode had vermoedelijk een betere verwijdering van systematische fouten mogelijk gemaakt. Voor Brabant leverde deze methode in ieder geval gunstige resultaten op 1.

Een laatste beschouwing betreffende de lonen heeft betrekking op het in aanmerking nemen van het aantal werkdagen per jaar voor de berekening van het looninkomen. Noordegraaf heeft zeer interessante informatie verzameld over de invloed van de Hervorming op de evolutie van het aantal werkdagen per jaar, en heeft op dit gebied baanbrekend werk verricht. De idee om deze factor te integreren in het inkomensonderzoek is dan ook bijzonder lofwaardig. De manier waarop dit is geschied, kan echter niet helemaal bevredigend worden genoemd. De Vries heeft hier opnieuw, en ons inziens terecht, methodologische bezwaren geopperd. Noordegraaf veronderstelt dat de vermindering van het aantal feestdagen, dat wil zeggen de respectieve verhoging van het aantal werkdagen, zich pas vanaf 1540 effectief voordeed en dat ze dan in twee trappen geschiedde, met name in 1540 en in 1575. Beide veronderstellingen zijn niet vanzelfsprekend. De viering van de 'geboden feestdagen' was reeds geruime tijd vóór 1540 aan een vermindering toe. Naar alle waarschijnlijkheid was deze vermindering bovendien een geleidelijk proces, tenzij kan worden aangetoond dat de stadsmagistraat van Haarlem en Leiden op een bepaald ogenblik het aantal feestdagen effectief heeft afgeschaft. Een dergelijke aanwijzing blijkt niet voorhanden. Het ware dan ook beter geweest de overgang van het aantal werkdagen per jaar van 245 naar 260 in 1540 en van 260 naar 275 in 1575 door een geleidelijke interpolatie tussen 1510 en 1575 in het jaartotaal te integreren.

Het probleem van de conjuncturele en structurele werkloosheid wordt door Noordegraaf opgelost door te veronderstellen dat de werkloosheid zich tussen 1450 en 1650 situeert

1 H. van der Wee, The Growth of the Antwerp Market and the European Economy (FourteenthSixteenth Centuries) ('s-Gravenhage, 1986) I, 39, 42-43, 134, 142, 149, 477, 507. 
op een constant gemiddeld niveau van 20 dagen per jaar. Het maximum aantal werkdagen per jaar in een toestand van volledige werkgelegenheid (geschat op 265 dagen vóór 1540, op 280 tussen 1540 en 1575, en op 295 na 1575) wordt derhalve in de berekeningen van het effectieve jaarinkomen steeds met 20 verminderd. Een dergelijke ingreep lijkt ons te willekeurig. Beter ware geweest, zoals De Vries suggereert, de berekening te maken op basis van het maximum aantal werkdagen per jaar, - een maximum dat vrij accuraat kan worden berekend voor de hele periode - en dan door middel van een conjunctuurindex een correctie hierop uit te voeren om de werkloosheidsgraad in de berekening van het jaarinkomen te integreren: de werkgelegenheidsindex die wijzelf voor de Westbrabantse steden hebben samengesteld voor de periode 1450-1600 had eventueel als vertrekpunt kunnen dienen ${ }^{2}$, eventueel ook statistische gegevens afkomstig uit de Haarlemse en Leidse stadsrekeningen.

Om de ontwikkeling van de levensstandaard te kunnen berekenen, toetst Noordegraaf zijn jaarlijkse looninkomens uit de Haarlemse en Leidse bouwsector aan de jaarlijkse tarwe- en roggeprijzen in Leiden en Utrecht. De Vries verkiest volledige indexcijfers boven graanprijzen, en meent dat de indexcijfers door Posthumus samengesteld, hiervoor in aanmerking konden komen. Noordegraaf vindt de methode van de indexcijfers natuurlijk ook de beste maar de cijfers die door Posthumus werden samengesteld, worden terecht als verouderd en voorbijgestreefd opzijgeschoven. Als alternatieve oplossing neemt Noordegraaf dan de jaarlijkse tarwe- en roggeprijzen in Leiden en Utrecht. Dit is geen gelukkige keuze. Noordegraaf veronderstelt dat brood de voeding van de bouwvakarbeiders in Holland volledig beheerste. Zo ja, dan waren broodprijzen beter geweest dan graanprijzen. De prijs van het brood wijkt immers af van die van de granen. Bovendien verschillen deze afwijkingen naar gelang de graanprijzen hoog of laag zijn. Aan de gebruikte graanprijzen kleven bovendien ook enkele gebreken: sommige zijn geen eigenlijke marktprijzen, maar het resultaat van zettingen, die tot doel hebben betalingen in natura om te zetten in betalingen in geld. Dergelijke zettingen verschilden naar gelang de prijsconjunctuur: zij volgden meestal vrij getrouw de markttoestand bij lage graanprijzen, maar bleven achter op de marktontwikkeling bij hoge graanprijzen.

Tenslotte nog deze opmerking: recent onderzoek betreffende zestiende-eeuwse voedingsbudgetten in Brabant ${ }^{3}$, heeft uitgewezen dat brood in het voedingsbudget van de middeninkomens wel een centrale plaats innam, maar zeker geen exclusieve, zelfs niet bij hongersnood en scherpe crisis. Het is dan ook jammer dat Noordegraaf bij een studie van dergelijke envergure geen poging heeft ondernomen om zijn berekeningen betreffende de levensstandaard een weinig uit te breiden. We hebben destijds voor dagloners bedrijvig in de bouwsector van enkele Westbrabantse steden, een jaarlijkse welvaartsmarge gereconstrueerd ${ }^{4}$. Aan de hand van een budget voor essentiële voedingswaren in de groep van de lagere middeninkomens, hebben wij berekend wat een gezin van 2 ouders en 3 kinderen jaarlijks aan inkomen nodig had om deze essentiële voedingswaren te kunnen aanschaffen. Wij hebben deze bedragen per jaar afgetrokken van het totale jaarinkomen van geschoolde en ongeschoolde dagloners (rekening houdend met winter- en

2 Ibidem, I, 539-544 en III, 92-93.

3 E. Schokkaert, H. van der Wee, 'A Quantitative Study of Food Consumption in the Low Countries during the Sixteenth Century' (verschijnt binnenkort in The Journal of European EconomicHistory).

$4 \quad$ Van der Wee, The Growth, I, 539-544; II, 381-388 en III, 90-95. 
zomerlonen, met geboden feestdagen en met de macro-schommelingen in de werkgelegenheid). Het residuaal bedrag (telkens in een percentage tot het jaarinkomen omgezet) gaf het procentueel aandeel van het totale jaarinkomen weer, dat ieder jaar aan nietessentiële voedingswaren kan worden besteed. De samenvoeging van de jaarlijkse percentages tot een reeks produceerde een curve die toeliet de ontwikkeling van de welvaartsmarge in enkele welbepaalde inkomensgroepen jaar na jaar te volgen. Een trendberekening bezorgde bovendien de mogelijkheid de fundamentele tendensen af te zonderen.

Het Hollandse bronnenmateriaal, hoewel gebrekkiger dan het Brabantse, maakte het, ons inziens, mogelijk een analoge berekening uit te voeren. De resultaten ervan zouden ons een scherper beeld hebben gegeven hoe de levensstandaard zich in enkele inkomensgroepen van twee Hollandse steden heeft ontwikkeld.

Het derde en laatste deel van ons betoog betreft het probleem van de interpretatie. Hier komt niet alleen de interpretatie van de concrete onderzoeksresultaten aan bod, maar bovendien de historische interpretatie als zodanig, daar ze in de discussie eveneens een belangrijke plaats inneemt.

Bij de interpretatie van de concrete onderzoeksresultaten zijn Noordegraaf en De Vries het met elkaar eens dat de grondiger studie van Noordegraaf, trendmatig gezien, de vroegere op beperkt materiaal gesteunde conclusies van De Vries, bevestigen. Hollands reële lonen, en daarvan afgeleid de levensstandaard ontwikkelden zich tijdens de zestiende en begin zeventiende eeuw, zij het met onderbrekingen, in gunstige zin, parallel met wat in Antwerpen zich voordeed, verschillend met wat in de rest van Europa geschiedde. De nominale lonen vormden een cruciale variabele bij de interpretatie van deze hoofdconclusie: ze stegen in de Hollandse steden grosso modo tussen 1540 en 1635, min of meer parallel met Antwerpen, maar in fel contrast met de rest van Europa. Hoe de specifieke ontwikkeling van de Hollandse lonen verklaren?

Noordegraaf verwijst naar drie hoofdverklaringen. De eerste, volgens Noordegraaf niet de belangrijkste, is de algemene prijsstijging. Zelfs in deze genuanceerde termen wordt ze voor wat Holland betreft door De Vries op theoretische gronden verworpen. Ook statistisch gesproken, blijkt De Vries aan het rechte eind te trekken: er is inderdaad tendentieel gezien geen positieve correlatie te bespeuren tussen de beweging van de Hollandse prijzen en die van de Hollandse nominale lonen, eerder het tegendeel. Noordegraaf heeft echter, feitelijk gezien, toch ook gelijk. Ten eerste op korte termijn: in tijden van ernstige crisis gebeurde het soms dat de prijsstijging aanleiding werd voor de overheid om een algemene loonsverhoging toe te staan, die effectief werd toegepast; omgekeerd gaven ook muntsaneringen niet zelden aanleiding tot prijsdalingen en tot gelijktijdige loonsverminderingen. Op lange termijn gezien, kan een stijgende tendens van de prijzen op de lonen soms positief inwerken, zij het met vertraging: vooral wanneer de loontrekkenden, als belangengroep, een machtspositie innamen in het stadsbestuur, kwamen dergelijke aanpassingen voor. De Vries zou hierop antwoorden dat de institutionele factoren hier toonaangevend zijn en de prijzen als zodanig niet meer als een cruciale verklaringsvariabele fungeren. Dit neemt niet weg dat beide samen als mogelijke belangrijke verklaringsvariabele in aanmerking komen.

Als tweede hoofdverklaring voor de stijging van de nominale lonen wordt de stijging van de arbeidsproduktiviteit genoemd. Noordegraaf en De Vries zijn het hierover eens, 
hoewel De Vries, steunend op theoretische gronden, de binding beperkt tot de groei van het reële loon. Het is jammer dat in de discussie niet dieper op het probleem van de hogere arbeidsproduktiviteit wordt ingegaan, want hier raken we een kernpunt in de verklaring van Hollands specifieke welvaartsontwikkeling. Was het organisatorische vooruitgang of was het technologische vooruitgang? Geschiedde deze vooruitgang vooral in de landbouw of vond die vooral in de steden plaats? In welke sectoren? Waren het vooral infrastructurele verbeteringen op initiatief en onder leiding van de stedelijke, rurale of gewestelijke overheid? Of waren het vooral verbeteringen onder de impuls van de landbouwers zelf, of van de stedelijke ambachtslieden, kooplieden en ondernemers? Lag het zwaartepunt in de zestiende of in de zeventiende eeuw? Deze kwesties komen noch in het boek, noch in de discussie ter sprake.

Als derde hoofdverklaring wordt de ontwikkeling van de arbeidsmarkt, met name de wisselwerking tussen arbeidsaanbod en arbeidsvraag, in aanmerking genomen. In het boek en in de discussie wordt aan deze kwestie een grote aandacht besteed. Noordegraaf ging in zijn boek uit van de assumptie dat een stijgende arbeidsvraag in het preindustriële Holland slechts aanleiding gaf tot stijgende nominale lonen wanneer het arbeidsaanbod (inclusief de verdoken werkloosheid) uitgeput raakte. Omgekeerd leidde een dalende arbeidsvraag niet tot een vermindering van de nominale lonen, maar tot een vermindering van het aantal gepresteerde werkdagen per jaar: de starheid van de nominale lonen zou dan te wijten zijn aan institutionele factoren, zoals overheidsinmenging tot handhaving van de lonen. De Vries heeft op theoretische gronden aangetoond dat dit arbeidsmarktmodel te simplistisch is. Noordegraaf geeft dit in feite grif toe, maar hij gaat niet akkoord met De Vries' bewering dat hierdoor de factoren bevolking, migratie, jaarlijkse arbeidsduur en voorkeur voor vrije tijd in de analyse worden verwaarloosd. Er werd inderdaad met deze factoren rekening gehouden, zij het op een intuïtieve en onsystematische wijze. Noordegraafs analyse van de arbeidsmarkt is daarom niet diepgaand genoeg. Het alternatief arbeidsmodel dat De Vries aanreikt is ongetwijfeld een steviger theoretisch kader voor een diepgaand onderzoek naar de invloed van de arbeidsmarkt op de ontwikkeling van de levensstandaard van de loontrekkenden. Maar ook hier blijft er een reëel probleem bestaan om de institutionele elementen, die de normale werking van de arbeidsmarkt in de zestiende en zeventiende eeuw op systematische wijze verstoorden, in het model in te bouwen.

Deze laatste opmerking brengt ons tot het laatste punt: de Methodenstreit, zoals ze in de discussie tot uiting komt. Noordegraaf en De Vries zijn het in wezen op vele punten met elkaar eens, hoewel dit bij een oppervlakkige lezing niet zo onmiddellijk blijkt. Beiden menen dat een grondig bronnenonderzoek en een scherpe bronnenkritiek een noodzakelijke beginvoorwaarde vormen voor iedere historische studie die wetenschappelijk wil zijn. Beiden zijn er ook ten volle van overtuigd dat wetenschappelijk onderzoek niet tot het opstapelen van eruditiemateriaal beperkt mag blijven: aan de heuristiek en bronnenkritiek moet een verklarende interpretatie worden toegevoegd, en wat meer is, 'the data do not speak for themselves' tijdens deze démarche.

Beiden zijn het er ook over eens dat het formuleren van een werkhypothese om de interpretatiefase wetenschappelijk op gang të brengen wenselijk is. Beiden vinden dat concepten en theorieën uit de sociale wetenschappen de opbouw van de werkhypothese kunnen verstevigen. Beiden menen ook dat kwalitatieve informatie en intuitie de op- 
bouw van deze werkhypothese op substantiële wijze kunnen verrijken. Noordegraaf beklemtoont hierbij terecht het grote belang van de kwalitatieve en intuitieve inbreng. De Vries wijst, eveneens terecht, op de bijzondere verklaringskracht die kan uitgaan van het integreren van theoretische kennis.

Niettegenstaande al deze overeenkomsten blijken de twee standpunten toch ergens uit elkaar te lopen. Noordegraaf meent dat het gebruik van concepten en theorieën uit de sociale wetenschappen aanleiding kan geven tot het formuleren van werkhypothesen die wegens de ingebouwde anachronismen of wegens de vele assumpties zo ver van de werkelijkheid verwijderd liggen, dat ze iedere relevantie voor het verklaren van het bestudeerde verschijnsel missen. Het is een feit dat een dergelijke geschiedschrijving bestaat. Noordegraaf heeft gelijk deze af te keuren, en een direct contact met de bronnen aan te bevelen om de kloof tussen theorie en werkelijkheid te helpen vermijden. Noordegraaf heeft echter geen gelijk wanneer hij deze kritiek naar De Vries toe richt. De Vries staat tijdens zijn onderzoek steeds dicht bij de bronnen, en gaat steeds zorgvuldig te werk bij het kiezen van theorieën, die hij bovendien zeer goed kent. Noordegraaf erkent trouwens zelf in de discussie dat het door De Vries voorgestelde arbeidsmarktmodel een beter vertrekpunt is voor de interpretatie van de loonontwikkeling in Holland, dan zijn eigen werkmodel.

Noordegraaf wijst ook op de ongelukkige neiging van vele historici in de deeldisciplines om de theoretische kennis in een voor niet-specialisten ontoegankelijke vaktaal in de interpretatie in te bouwen. Het is ongetwijfeld juist dat theoretisch jargon heel wat historische publikaties overwoekert en dat er veel te wieden valt op dit gebied. Dezelfde kritiek kan worden geleverd op de toepassing van beschrijvende en verklarende statistiek. Indien echter theorieën uit de sociale wetenschappen en cliometrische toepassingen de verklarende interpretatie in de geschiedenis kunnen verbeteren, en indien het gebruik van vaktaal hiertoe noodzakelijk is, dan blijft het nog steeds mogelijk om de conclusies - en zelfs de aangewende methodes - in een vereenvoudigde, literaire vorm voor het breder publiek toegankelijk te maken, zelfs al moet men hiervoor een beroep doen op tussenpersonen, die de gave bezitten van vereenvoudigde voorstelling en van literaire vormgeving.

De Vries stelt zich van zijn kant erg kritisch op tegen historisch onderzoek dat steunt op gebrekkige steekproeven, op onvoldoende bronnenkritiek en op oppervlakkige interpretatie. Niemand zal hem daarin tegenspreken. Wanneer De Vries echter zijn opmerkingen toepasselijk verklaart op Noordegraafs boek, kan men deze kritiek als te scherp ervaren. Noordegraafs studie vertoont ongetwijfeld een reeks spijtige tekortkomingen, maar ze heeft ook verdiensten: ze is in ieder geval een eerste systematische poging om de ontwikkeling van de levensstandaard in Holland tussen 1450 en 1650 kwantitatief te meten en deze meting met kwalitatief bronnenmateriaal aan te vullen. Ze is ook een eerste poging om de ontwikkeling van de levensstandaard in Holland systematisch te verklaren. Op beide terreinen werden interessante resultaten geboekt, hoewel ze voor kritiek vatbaar zijn. De weg ligt open voor een breder opgezet en diepgaander onderzoek: hiertoe nodigt Noordegraaf trouwens uit. 


\title{
De nieuwe 'memorialen Rosa'
}

\author{
Recensieartikel door C. L. Verkerk
}

R. W. G. Lombarts, e.a., ed., Memorialen van het Hof (den Raad) van Holland, Zeeland en West-Friesland, van den secretaris Jan Rosa delen IV, V en VI (Rechtshistorisch Instituut, serie I, deel IV; Leiden: Brill, Universitaire Pers Leiden, 1982, xi + 652 blz., f80,-, ISBN 900406880 5); Idem, VII, VIII, IX, X (Idem V; Idem, 1985, ix + 291 blz., f80,-, ISBN 900407729 4).

In 1929 verzorgden de Leidse hoogleraren A. S. de Blécourt en E. M. Meijers de uitgave van regesten en transcripties uit de eerste drie registers van de grafelijke Raad van Holland, zoals die was georganiseerd na de totstandkoming van de zoen van Delft. Onder dezelfde titel als in 1929, in de wandeling aangeduid als 'Memorialen Rosa', zijn nu de zeven volgende registers van het Hof van Holland uitgegeven door de Leids-Amsterdamse hoogleraar J. Th. de Smidt met zijn Leidse medewerkers. Het ligt in de bedoeling in een volgend deel de overige drie 'Memorialen Rosa' te publiceren samen met het memoriaal $\mathrm{T}$ cas $\mathrm{N}$, dat afkomstig is uit het oude leen- en registerkamerarchief van de graven van Holland, waar het werd bewaard bij de memorialen van de grafelijke raad uit de Beierse periode tot 1428 . Dit memoriaal T werd pas begonnen in 1445, gelijktijdig met deze drie 'Memorialen Rosa' (XI, XII en XIII).

De uitgave van 1929 werd genoemd naar de tweede griffier van de raad, Jan Rose, naar wie de eerste registers, zelf 'memorialen' of 'memoriaelboucken' genoemd, al sinds de zeventiende eeuw waren vernoemd, hoewel zij tot stand kwamen in de periode dat Jan Rose met meer anderen nog als secretaris bij de Raad werkte vanaf 1428. Alleen de laatste twee memorialen (XII en XIII) en het gelijktijdig tot stand gekomen memoriaal T cas $\mathrm{N}$ werden vervaardigd onder het griffierschap van Jan Rose, die in februari 1447 in die functie werd aangesteld als opvolger van Dire Boudijnszoon van Zwieten. Deze was als eerste in 1445 in de nieuw ingestelde functie van griffier aangesteld en onder hem kwam dan ook het elfde memoriaal tot stand. Ook dit memoriaal werd samen met alle voorgaande registers sinds 1428 naar zijn opvolger genoemd. Als secretaris komt Roses handtekening slechts een enkele keer in de registers voor ( 2 maal in het vijfde en 1 maal in het tweede), terwijl de handtekeningen van sommige andere secretarissen veel vaker zijn nagelaten in de registers. Mogelijk is de gewoonte om na Jan Rose de memorialen aan te duiden 'naar den op dat oogenblik vigeerende griffier' (T. S. Jansma, Raad en Rekenkamer in Holland en Zeeland tijdens hertog Philips van Bourgondië (Utrecht, 1932) 94) van invloed geweest op de vernoeming van' de vroegste memorialen naar de laatst levende, tweede, griffier, onder wie een wijziging van de registratuur bij het Hof tot stand kwam. De 'memorialen van partijen', de zogeheten B-serie, waartoe memorialen III, VI, VII en IX behoren, werden toen opgesplitst in een reeks memorialen die 'rolboeken' genoemd zouden gaan worden, en een reeks sententieregisters (zie daarvoor het onlangs verschenen artikel van R. W. G. Lombarts, 'Nota te setten dair 't behoirt. Enkele opmerkingen over de oudste registers van het archief van het Hof van Holland', Nederlands Archievenblad (1985) 367-374). Als er al een secretaris op grond van het voorkomen van zijn handtekening in verschillende registers het recht zou kunnen op- 